\title{
Thrombopoietin Receptor Agonists are Effective in Treating Chemotherapy-induced Thrombocytopenia in Patients with Gliomas Undergoing Myelotoxic Treatment
}

\author{
Christopher Dardis ${ }^{\circledR}{ }^{\bowtie}$, Kelly Milton ${ }^{1}$, Neel Patel ${ }^{2}$ \\ 1. Dept. Neurology, Barrow Neurological Institute, 240 W Thomas Rd, Phoenix, AZ 85013, USA \\ 2. Dept. Family Medicine, Hidalgo Medical Services, 530 De Moss St, Lordsburg, NM 88045, USA \\ $\bowtie$ Corresponding author: christopherdardis@gmail.com, Office 602406 6238, Fax 6024066260 \\ (c) Ivyspring International Publisher. This is an open access article distributed under the terms of the Creative Commons Attribution (CC BY-NC) license \\ (https://creativecommons.org/licenses/by-nc/4.0/). See http://ivyspring.com/terms for full terms and conditions.
}

Received: 2016.11.20; Accepted: 2016.12.23; Published: 2017.01.01

\begin{abstract}
Introduction: Chemotherapy-induced thrombocytopenia (CIT) is the principal dose-limiting toxicity in patients with glioma undergoing chemotherapy, affecting up to $25 \%$ of such patients.

Methods: This is a retrospective, unblinded case series. Patients undergoing chemotherapy for glioma (astrocytoma, oligodendroglioma or glioblastoma) who developed CIT were prescribed a thrombopoetin receptor agonist (TRA, i.e. eltrombopag or romiplostim). Doses were increased on a weekly basis, as required, until platelets were $>100 \times 10^{9} / \mathrm{L}$ or this goal was not achieved with maximum dosing. Chemotherapy was resumed if possible and patients were followed as long as they remained on treatment.

Results: A TRA was effective for CIT in 26/27 (96\%). Once treated, all patients were able to resume chemotherapy as planned. Chemotherapy was continued for a median (range) of 11 months (2-28) and patients received an additional $5625(0-16000) \mathrm{mg} / \mathrm{m}^{2}$ of temozolomide, 0 $(0-720) \mathrm{mg} / \mathrm{m}^{2}$ of lomustine and $75(0-390) \mathrm{mg} / \mathrm{kg}$ of bevacizumab. No patients in this series stopped chemotherapy due to completion of a planned regimen.

Conclusions: By using TRAs for CIT, we were able to continue chemotherapy for a longer time and at higher doses than would have been possible without this treatment. A larger series is necessary in order to determine whether this translates into improved clinical outcomes. CIT is a common problem throughout oncology, and therefore we believe that use of TRA's for this purpose should be further investigated.
\end{abstract}

Key words: glioma, thrombopoietin, thrombocytopenia, antineoplastic agents

\section{Introduction}

CIT refers to a platelet count below the lower limit of normal due to chemotherapy. In practice, a threshold of $<100 \times 10^{9} / \mathrm{L}$ is typically used. It may be divided into grades to indicate severity, as shown in Table 1. CIT is the most common reason for stopping chemotherapy (or reducing the dose) in patients with glioma. Temozolomide, bevacizumab and lomustine are typically used to treat gliomas, and all are myelotoxic.

\section{Treatment of gliomas}

Our own practice, in patients newly diagnosed with glioma where chemotherapy is prescribed, follows the Stupp regimen [1]. This uses temozolomide $75 \mathrm{mg} / \mathrm{m}^{2}$ po daily for 6 weeks (concurrent with 
radiotherapy) followed by at least 6 and ideally 12 cycles. These cycles are for $5 / 28$ days. The first cycle is usually $150 \mathrm{mg} / \mathrm{m}^{2}$ and thereafter increased to 200 $\mathrm{mg} / \mathrm{m}^{2}$. Treatment beyond 12 months is individualized.

If progression occurs, we usually add bevacizumab at $10 \mathrm{mg} / \mathrm{m}^{2}$ iv every 2 weeks. We change the alkylating agent from temozolomide to lomustine $100 \mathrm{mg} / \mathrm{m}^{2}$ po every 6 weeks, either at this time or if further progression occurs. Treatment is individualized and bevacizumab is sometimes used earlier in the course of treatment. A second course of radiotherapy with concurrent temozolomide, usually over 3 weeks, is used on occasion.

Once the platelet count drops below $100 \times 10^{9} / \mathrm{L}$, in a patient on lomustine or temozolomide, chemotherapy dosing is typically decreased, as further decline in the platelet count is almost inevitable without modification of treatment. A threshold of $50 \times 10^{9} / \mathrm{L}$ is used with bevacizumab, which is less myelotoxic, when this agent is used alone.

Table 1. Grades of severity of thrombocytopenia, as per the CTCAE [2]. LLN - lower limit of normal.

\begin{tabular}{cl}
\hline Grade & Platelets \\
\hline 1 & $<$ LLN $-75 \times 10^{9} / \mathrm{L}$ \\
2 & $<75 \times 10^{9} / \mathrm{L}-50 \times 10^{9} / \mathrm{L}$ \\
3 & $<50 \times 10^{9} / \mathrm{L}-25 \times 10^{9} / \mathrm{L}$ \\
4 & $<25 \times 10^{9} / \mathrm{L}$ \\
\hline
\end{tabular}

\section{Prevalence of CIT}

$25 \%$ of patients on temozolomide monotherapy developed CIT in the largest series to date which addresses this question $(n=101)$ [3]. Cumulative dosing of temozolomide was the only variable studied associated with CIT. Platelet counts of $<50$ occurred in $8 \%$ of patients.

$20 \%$ were affected by counts of $<50$ in a series of 52 patients [4]. In $80 \%$ of those affected, toxicity occurred during, or soon after, initial concurrent chemo-radiotherapy. $90 \%$ of sufferers stopped chemotherapy due to CIT.

$10-11 \%$ of those in clinical trials of glioblastoma using temozolomide developed CIT; such patients tend to have a better performance status than an unselected group of patients with glioma $[5,6]$.

Bevacizumab, when added to a variety of cancer regimens is associated with a higher rate of CIT (relative risk 1.22; $\mathrm{p}=0.047$ ) [7].

$44-54 \%$ of those using lomustine in clinical trials of glioma treatment develop platelets of $<50$. $[8,9]$. When lomustine is combined with bevacizumab, the development of platelets of $<50$ has been reported to be dose-dependent, affecting $63 \%$ of patients taking lomustine $110 \mathrm{mg} / \mathrm{m}^{2}$ po q6 wks vs. $9 \%$ of patients on lomustine $90 \mathrm{mg} / \mathrm{m}^{2}$ [10].

\section{Materials and Methods}

Ethical approval for this work was obtained from the Institutional Review Board of St. Joseph's Hospital.

We reviewed patients who had received a TRA in our practice over the period Jul 2014 to Dec 2015 while receiving chemotherapy for glioma (WHO grades II, III and IV). Treatment was instigated at the discretion of the treating physician but was typically employed when platelet counts had fallen below 100 . None of these patients were using forms of chemotherapy apart from the three already highlighted. With one exception (discussed below) none had other factors predisposing to thrombocytopenia.

The TRA eltrombopag was used when possible, as oral administration was preferable for patients. However, treatment decisions were typically dependent on insurer preference and romiplostim (administered subcutaneously) was used in some cases. Dosing was based on existing guidelines for the use of TRAs in the treatment of immune thrombocytopenia. Once platelet counts reached $>100$, we attempted to resume chemotherapy as planned.

We recorded the time from starting chemotherapy to the time of the nadir of platelet counts, the value of the count at that time and the cumulative dosing of chemotherapy. We recorded time until last observation, treatment effectiveness, outcome (treatment ongoing, hospice care or death) as well as the additional cumulative chemotherapy given since the platelet nadir.

Analysis was performed using $\mathrm{R}$ and is given as Supplementary Material [11,12]. Herein, for continuous variables, results are generally given as median [interquarile range (IQR)]. Time-to-event data is given as a median with a $95 \%$ confidence interval (NA indicates not applicable, as insufficient numbers of events had occurred).

\section{Results and Discussion}

40 patients were prescribed a TRA over the 18 months reviewed. Of these, 13 did not start treatment, typically due to lack of insurance coverage and in some cases due to progressive disability resulting in cessation of chemotherapy. These cases are not reviewed further here.

Table 2 shows the 27 individual patients and summary statistics for each variable; the complete dataset is part of the Supplementary Material. 


\section{Nadir}

The lowest platelet count was 69 [46-86] when a TRA was instituted. This nadir was reached 4.4 [2.2 12] months after starting chemotherapy; the nadir occurred within 3 months of starting treatment in 9/27 (33\%) patients.

Cumulative doses of chemotherapy prior to developing CIT and thereafter until the last follow-up are shown in Table 3. When the nadir was reached, $41 \%$ had used at least some bevacizumab and $19 \%$ at least some lomustine.

Eltrombopag was used in 22/27 (81\%) of patients; the others received romiplostim. Platelets of $>100$ were restored in most cases with the standard starting dose of the TRA: for eltrombopag, 17/22 (77\%) with $50 \mathrm{mg}$ daily; for romiplostim 4/5 (80\%) with 1 microg $/ \mathrm{kg} /$ week.

\section{Subsequent treatment}

Nearly all patients were able to continue treatment as originally planned. The sole exception (Table 2, ID=26) was a survivor of childhood leukemia (AML) who had received systemic chemotherapy at that time. Pancytopenia, with platelets of 7, developed soon after initial chemo-radiotherapy. Little improvement was seen despite maximal dosing of a TRA. Thus, no further chemotherapy was possible.

Excluding this individual, the time to stopping chemotherapy (hospice care or death) was 15.6 [10.3 NA] months. At the time of last follow-up, 14/27 (52\%) had stopped chemotherapy (Figure 1). Overall time on chemotherapy was encouraging, particularly for those with glioblastoma, whose time on chemotherapy was 32.3 [16.9 - NA] months (Figure 2).

Table 2. Patients receiving a TRA. Last row shows summary statistics, given as percentages or median [interquartile range].

\begin{tabular}{|c|c|c|c|c|c|c|c|c|c|c|c|c|c|c|c|c|}
\hline \multirow[t]{2}{*}{ ID } & \multirow{2}{*}{$\begin{array}{l}\text { WHO } \\
\text { grade }\end{array}$} & \multirow[t]{2}{*}{ Age } & \multirow[t]{2}{*}{ Sex } & \multirow{2}{*}{$\begin{array}{l}\text { Platelet } \\
\text { nadir }\end{array}$} & \multirow{2}{*}{$\begin{array}{l}\text { Months } \\
\text { to nadir }\end{array}$} & \multicolumn{3}{|c|}{ Cumulative, before nadir } & \multirow[t]{2}{*}{$\mathrm{T}$} & \multirow[t]{2}{*}{$\mathrm{D}$} & \multirow[t]{2}{*}{$\mathrm{E}$} & \multirow{2}{*}{$\begin{array}{l}\text { Months to } \\
\text { last } \mathrm{f} / \mathrm{up}\end{array}$} & \multirow[t]{2}{*}{$\mathrm{O}$} & \multicolumn{3}{|c|}{ Additional cumulative } \\
\hline & & & & & & tem & bev & lom & & & & & & tem & bev & lom \\
\hline 1 & 3 & 58 & $\mathrm{~m}$ & 98 & 10.68 & 6900 & 170 & 0 & $\mathrm{e}$ & 25 & $\mathrm{y}$ & 14.66 & $\mathrm{~d}$ & 6750 & 50 & 0 \\
\hline 2 & 4 & 58 & $\mathrm{~m}$ & 85 & 11.00 & 9900 & 70 & 0 & $\mathrm{e}$ & 50 & $\mathrm{y}$ & 28.18 & $\mathrm{~h}$ & 9000 & 320 & 0 \\
\hline 3 & 4 & 72 & $\mathrm{f}$ & 41 & 5.00 & 3900 & 0 & 0 & $\mathrm{e}$ & 50 & $\mathrm{y}$ & 4.6 & $\mathrm{~h}$ & 5000 & 0 & 0 \\
\hline 4 & 4 & 41 & $\mathrm{f}$ & 58 & 19.82 & 4425 & 60 & 300 & $\mathrm{e}$ & 50 & $\mathrm{y}$ & 2.04 & $\mathrm{~h}$ & 2000 & 30 & 0 \\
\hline 5 & 4 & 72 & $\mathrm{~m}$ & 64 & 3.62 & 3900 & 0 & 0 & $\mathrm{e}$ & 200 & $\mathrm{y}$ & 19.53 & o & 6000 & 240 & 0 \\
\hline 6 & 4 & 73 & $\mathrm{~m}$ & 62 & 0.03 & 0 & 0 & 0 & $\mathrm{e}$ & 50 & $\mathrm{y}$ & 9.4 & $\mathrm{~h}$ & 9850 & 60 & 0 \\
\hline 7 & 4 & 57 & $\mathrm{~m}$ & 69 & 20.12 & 17900 & 320 & 280 & $\mathrm{e}$ & 50 & $\mathrm{y}$ & 21.4 & o & 0 & 300 & 720 \\
\hline 8 & 3 & 44 & $\mathrm{f}$ & 77 & 28.96 & 23475 & 100 & 0 & e & 50 & $\mathrm{y}$ & 21.57 & o & 8000 & 260 & 500 \\
\hline 9 & 4 & 49 & $\mathrm{f}$ & 18 & 26.14 & 17900 & 30 & 200 & e & 50 & $\mathrm{y}$ & 6.02 & $\mathrm{~h}$ & 0 & 45 & 200 \\
\hline 10 & 4 & 35 & $\mathrm{f}$ & 61 & 1.61 & 3150 & 0 & 0 & $\mathrm{r}$ & 1 & $\mathrm{y}$ & 18.48 & o & 9750 & 110 & 100 \\
\hline 11 & 4 & 65 & $\mathrm{f}$ & 5 & 1.28 & 1575 & 0 & 0 & $\mathrm{r}$ & 1 & $\mathrm{y}$ & 15.62 & $\mathrm{~h}$ & 0 & 60 & 0 \\
\hline 12 & 4 & 62 & $\mathrm{f}$ & 50 & 1.94 & 3150 & 0 & 0 & $\mathrm{e}$ & 50 & y & 18.15 & o & 10750 & 230 & 0 \\
\hline 13 & 4 & 39 & $\mathrm{~m}$ & 75 & 4.14 & 5400 & 0 & 0 & e & 50 & $\mathrm{y}$ & 17.49 & o & 16000 & 390 & 0 \\
\hline 14 & 2 & 26 & $\mathrm{f}$ & 86 & 211.10 & 33775 & 80 & 100 & $\mathrm{e}$ & 50 & $\mathrm{y}$ & 16.14 & $\mathrm{~h}$ & 0 & 80 & 100 \\
\hline 15 & 4 & 60 & $\mathrm{f}$ & 94 & 1.64 & 3150 & 0 & 0 & e & 50 & $\mathrm{y}$ & 11.61 & $\mathrm{~h}$ & 12525 & 230 & 300 \\
\hline 16 & 2 & 38 & $\mathrm{f}$ & 79 & 1.18 & 3150 & 0 & 0 & $\mathrm{r}$ & 10 & $\mathrm{y}$ & 16.08 & o & 5250 & 60 & 0 \\
\hline 17 & 4 & 71 & $\mathrm{f}$ & 81 & 4.37 & 4650 & 20 & 0 & e & 50 & $\mathrm{y}$ & 4.9 & $\mathrm{~h}$ & 5000 & 100 & 0 \\
\hline 18 & 4 & 70 & $\mathrm{f}$ & 98 & 0.95 & 3150 & 0 & 0 & $\mathrm{r}$ & 1 & y & 4.44 & $\mathrm{~h}$ & 2000 & 0 & 0 \\
\hline 19 & 4 & 63 & $\mathrm{~m}$ & 95 & 5.42 & 5900 & 0 & 0 & $\mathrm{e}$ & 50 & $\mathrm{y}$ & 15.16 & o & 13000 & 0 & 0 \\
\hline 20 & 4 & 46 & $\mathrm{~m}$ & 40 & 71.47 & 56700 & 195 & 440 & $\mathrm{e}$ & 50 & $\mathrm{y}$ & 10.06 & $\mathrm{~h}$ & 0 & 195 & 700 \\
\hline 21 & 4 & 74 & $\mathrm{f}$ & 25 & 7.89 & 9900 & 0 & 0 & e & 150 & y & 5.72 & o & 5000 & 0 & 0 \\
\hline 22 & 4 & 64 & $\mathrm{~m}$ & 64 & 4.24 & 5900 & 10 & 0 & $\mathrm{e}$ & 50 & $\mathrm{y}$ & 10.32 & $\mathrm{~h}$ & 0 & 250 & 400 \\
\hline 23 & 2 & 51 & $\mathrm{f}$ & 34 & 9.21 & 6900 & 0 & 0 & $\mathrm{e}$ & 50 & $\mathrm{y}$ & 6.31 & o & 7000 & 0 & 0 \\
\hline 24 & 4 & 44 & $\mathrm{f}$ & 73 & 12.95 & 10900 & 50 & 0 & e & 50 & y & 8.28 & o & 9000 & 190 & 0 \\
\hline 25 & 4 & 63 & $\mathrm{f}$ & 92 & 3.06 & 4150 & 0 & 0 & $\mathrm{r}$ & 1 & $\mathrm{y}$ & 7.4 & o & 7000 & 0 & 0 \\
\hline 26 & 3 & 37 & $\mathrm{f}$ & 7 & 2.40 & 3150 & 0 & 0 & $\mathrm{e}$ & 150 & $\mathrm{n}$ & 3.85 & $\mathrm{~h}$ & 0 & 0 & 0 \\
\hline 27 & 4 & 69 & $\mathrm{~m}$ & 88 & 2.53 & 3150 & 0 & 0 & e & 100 & $y$ & 4.73 & o & 1500 & 70 & 0 \\
\hline & 2: $11 \%$ & 58 & f: $63 \%$ & 69 & 4.4 & 4650 & $\begin{array}{l}0 \\
{[0-55]}\end{array}$ & $\begin{array}{l}0 \\
00-0\end{array}$ & e: & & $\begin{array}{l}y: \\
96 \%\end{array}$ & 11 & o: & $\begin{array}{l}5625 \\
\end{array}$ & $\begin{array}{l}75 \\
\end{array}$ & $\begin{array}{l}0 \\
{[0-100]}\end{array}$ \\
\hline & & {$[44-0 /]$} & & {$[40-00]$} & {$[2.2-1<]$} & {$[0150-9900]$} & {$[0-50]$} & {$[0-0]$} & $01 \%$ & & & {$[0.1-1 / .2]$} & & {$[10<5-9000]$} & {$[34-200]$} & {$[0-100]$} \\
\hline
\end{tabular}

Abbreviations: tem - temozolomide; bev - bevacizumab; lom - lomustine. Cumulative dosing of chemotherapy is given in the following units: tem, lom $\mathrm{mg} / \mathrm{m} 2$; bev - mg/kg. T - treatment: e - eltrombopag; r - romiplostim. D - dose: eltombopag, 25 - 200 mg po daily; romiplostim, 1 -10 microg/kg subcut weekly. E - effective ? (i.e. platelets returned to $>100 \times 10^{9} / \mathrm{L}$ ). $\mathrm{O}$ - outcome: $\mathrm{d}$-died; $\mathrm{h}$ - hospice care; o - treatment ongoing. 

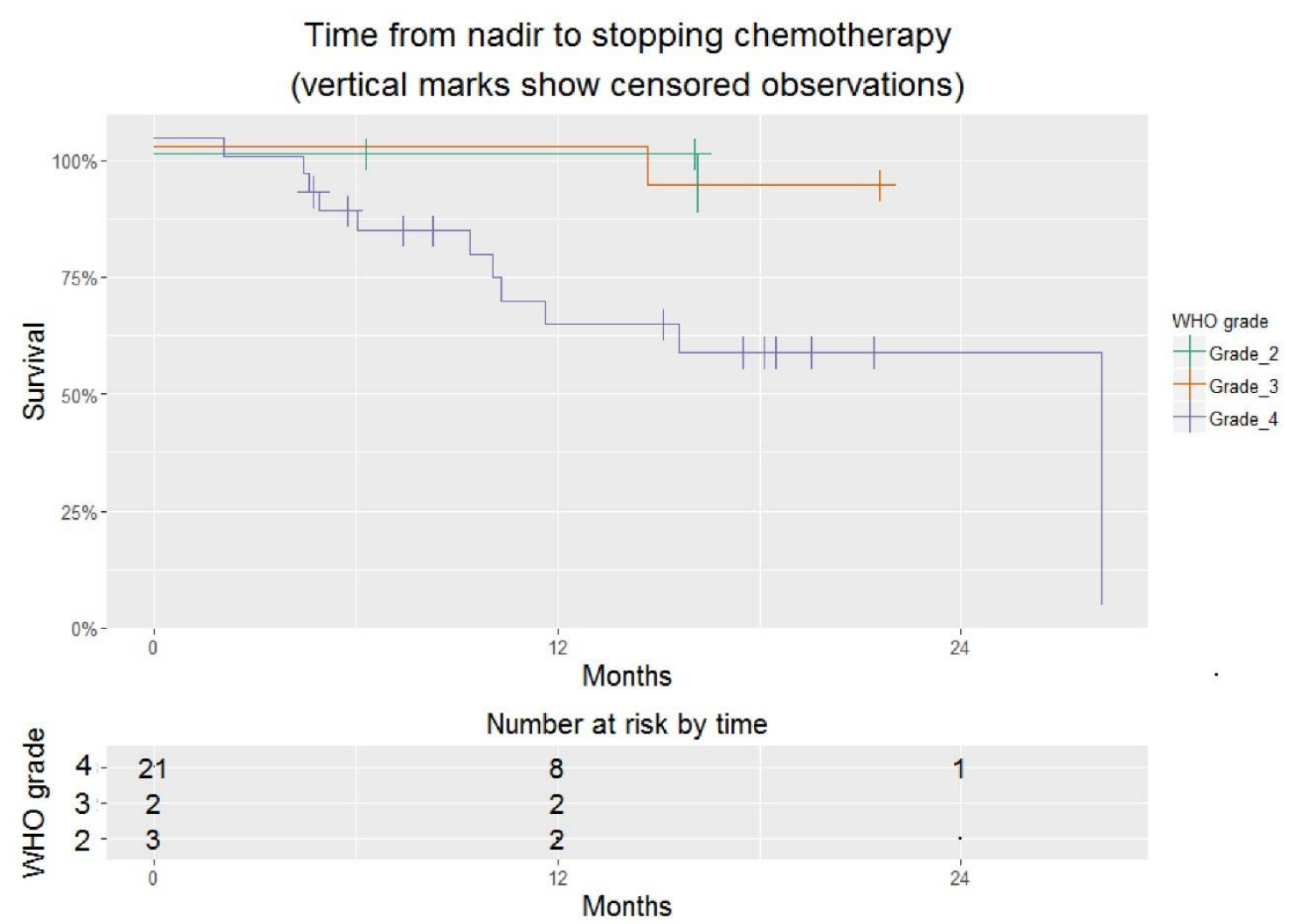

Figure 1. Time from platelet nadir to hospice referral or death for 26 patients treated successfully with a TRA. This is stratified by WHO grade. Where survival $=100 \%$ for all grades, lines are jittered to avoid overlap.

\section{Total time on chemotherapy}

(vertical marks show censored observations)
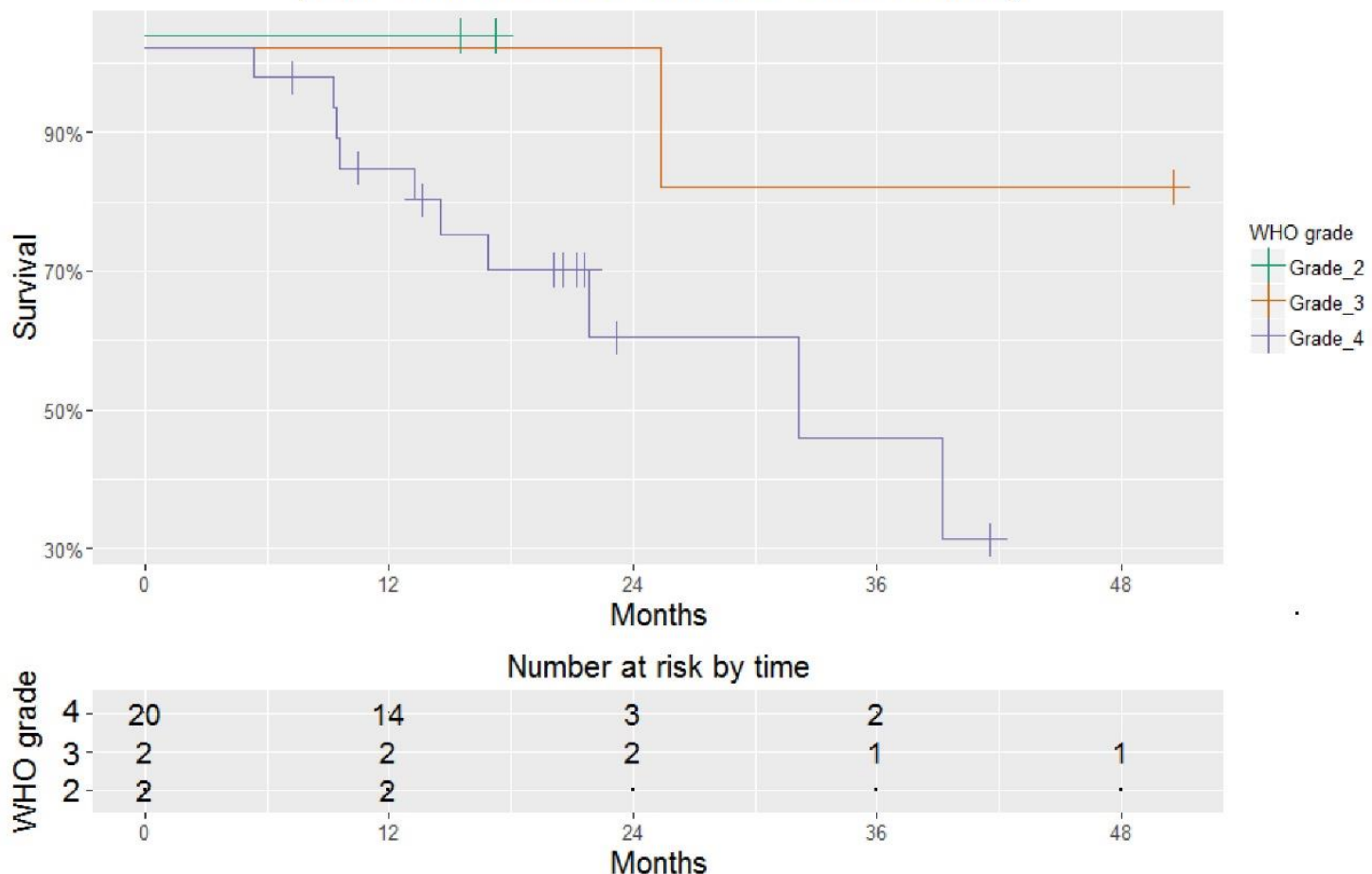

Figure 2. Total time on chemotherapy for 26 patients treated successfully with a TRA. This is stratified by WHO grade. Where survival=100\% for all grades, lines are jittered to avoid overlap. 
Table 3. Cumulative doses of chemotherapy received before and after starting a TRA. Values are median [IQR]. As an example, temozolomide $200 \mathrm{mg} / \mathrm{m}^{2}$ for $5 / 28$ days for 3 cycles $=3000 \mathrm{mg} / \mathrm{m}^{2}$.

\begin{tabular}{llll}
\hline & $\begin{array}{l}\text { temozolomide } \\
\mathrm{mg} / \mathrm{m}^{2}\end{array}$ & $\begin{array}{l}\text { bevacizumab } \\
\mathrm{mg} / \mathrm{kg}\end{array}$ & $\begin{array}{l}\text { lomustine } \\
\mathrm{mg} / \mathrm{m}^{2}\end{array}$ \\
\hline Before CIT & $4650[3150-9900]$ & $0[0-55]$ & $0[0-0]$ \\
After CIT & $5625[1625-9000]$ & $75[34-230]$ & $0[0-100]$ \\
\hline
\end{tabular}

\section{Side effects}

One patient had intractable itching after each dose of eltrombopag, which lasted 2-3 hr. These symptoms were tolerable once dosing was changed to twice/week and treatment continued as planned thereafter. There was one sudden unexpected death (Table 1, ID=1); we suspect this was a pulmonary embolism although no autopsy was performed.

\section{Discussion}

As shown, CIT was remediated in all patients but one and did not re-occur despite prolonged subsequent chemotherapy. CIT should be distinguished from the rarer aplastic anemia associated with temozolomide, as in our patient who did not respond to treatment [13].

Romiplostim has already been shown to be safe and effective in CIT in a series of 20 patients undergoing chemotherapy for a variety of cancers, including one patient with glioblastoma [14]. Of those who resumed chemotherapy, 14/15 (93\%) tolerated at least two additional cycles and 4/15 (27\%) continued treatment for an additional year or more.

Currently, the only FDA-approved agent for CIT is oprelvekin (IL-11) [15]. This requires daily subcutaneous dosing. The improvement in platelet counts tends to be less marked and side effects more common than with the TRAs.

\section{Conclusions}

Being that CIT is such a common problem in oncology, we encourage our colleagues to investigate TRAs as part of supportive care for other myelotoxic regimens. Given their effectiveness, a randomized trial may be hard to justify [16]. Without FDA approval for CIT, lack of insurance coverage may be a barrier to their use, at least in the USA.

\section{Supplementary Material}

Statistics. http://www.oncm.org/v02p0037s1.pdf

\section{Abbreviations}

CIT: chemotherapy-induced thrombocytopenia; TRA: thrombopoetin-receptor agonist; IQR: interquartile range.

\section{Competing Interests}

The authors have declared that no competing interest exists. No financial or material support was received for this work.

\section{References}

1. Stupp R Mason WP, van den Bent MJ et al. Radiotherapy plus concomitant and adjuvant temozolomide for glioblastoma. N Engl J Med. 2005;352(10):987-96. PMID: 15758009

2. [Internet] US department of health and human services. Common Terminology Criteria for Adverse Events (CTCAE) Version 4.03. Revised 14 June 2010. http://evs.nci.nih.gov/ftp1/CTCAE/

3. Simó $M$, Velasco $R$, Graus $F$ et al. Impact of antiepileptic drugs on thrombocytopenia in glioblastoma patients treated with standard chemoradiotherapy. J Neurooncol. 2012;108(3):451-8. PMID: 22407174

4. Gerber DE, Grossman SA, Zeltzman M, Parisi MA, Kleinberg L. The impact of thrombocytopenia from temozolomide and radiation in newly diagnosed adults with high-grade gliomas. Neuro Oncol. 2007;9(1):47-52. PMID: 17108062

5. Stupp R, Dietrich PY, Ostermann Kraljevic $S$ et al. Promising survival for patients with newly diagnosed glioblastoma multiforme treated with concomitant radiation plus temozolomide followed by adjuvant temozolomide. J Clin Oncol. 2002;20(5):1375-82. PMID: 11870182

6. Stupp R, Mason WP, van den Bent MJ et al. Radiotherapy plus concomitant and adjuvant temozolomide for glioblastoma. N Engl J Med. 2005;352(10):987-96. PMID: 15758009

7. Schutz FA, Jardim DL, Je Y, Choueiri TK. Haematologic toxicities associated with the addition of bevacizumab in cancer patients. Eur J Cancer. 2011;47(8):1161-74. PMID: 21470847

8. Wick W, Puduvalli VK, Chamberlain MC et al. Phase III study of enzastaurin compared with lomustine in the treatment of recurrent intracranial glioblastoma. J Clin Oncol. 2010;28(7):1168-74. PMID: 20124186

9. Walker MD, Alexander E Jr, Hunt WE et al. Evaluation of BCNU and/or radiotherapy in the treatment of anaplastic gliomas. A cooperative clinical trial. J Neurosurg. 1978;49(3):333-43. PMID: 355604

10. Taal W, Oosterkamp HM, Walenkamp AM et al. Single-agent bevacizumab or lomustine versus a combination of bevacizumab plus lomustine in patients with recurrent glioblastoma (BELOB trial): a randomised controlled phase 2 trial. Lancet Oncol. 2014;15(9):943-53. PMID: 25035291

11. R Core Team. R: A language and environment for statistical computing. R Foundation for Statistical Computing, Vienna, Austria. 2013.

12. Dardis C, Woolf EC, Scheck AC. Towards reproducible research: From data analysis (in R) to a typeset laboratory notebook (as. pdf) using the text editor Emacs with the'mp'package. F1000Research. 2015;4. DOI: 10.12688/f1000research.6800.2

13. Federal Drug Administration (FDA). Drug Safety Newsletter. Postmarketing Reviews. 2007; 1(1): 7.

14. Parameswaran R, Lunning $M$, Mantha $S$ et al. Romiplostim for management of chemotherapy-induced thrombocytopenia. Support Care Cancer. 2014;22(5):1217-22. PMID: 24414994

15. Bhatia M, Davenport V, Cairo MS. The role of interleukin-11 to prevent chemotherapy-induced thrombocytopenia in patients with solid tumors, lymphoma, acute myeloid leukemia and bone marrow failure syndromes. Leuk Lymphoma. 2007;48(1):9-15. PMID: 17325843

16. Smith GC, Pell JP. Parachute use to prevent death and major trauma related to gravitational challenge: systematic review of randomised controlled trials. BMJ. 2003;327(7429):1459-61 PMID: 14684649 